\title{
Erratum to: Safety and efficacy of a $100 \%$ dimethicone pediculocide in school-age children
}

Erin Speiser Ihde ${ }^{1 *}$, Jeffrey R. Boscamp ${ }^{2}$, Ji Meng Loh ${ }^{3}$ and Lawrence Rosen ${ }^{1}$

Following the publication of the original article [1], an error was noticed by the authors. The statistics shown in Figure Two do not accurately reflect the results outlined in the text. To correctly reflect the text, the "subjects with/without live lice" graph in Fig. 2 (Fig. 1 here) should state $98.2 \%$ for day 7 and $96.5 \%$ for day 14 (at current the graph states $90.2 \%$ for day 7 and $90.5 \%$ for day 14). The correct figure is attached to this erratum, for your reference.

\section{Author details}

${ }^{1}$ The Deirdre Imus Environmental Health Center ${ }^{\oplus}$, Hackensack University Medical Center, 30 Prospect Ave, Hackensack, NJ 07601, USA. ${ }^{2}$ Hackensack University Medical Center, The Joseph M. Sanzari Children's Hospital, 30 Prospect Avenue, Hackensack, NJ 07601, USA. ${ }^{3}$ Department of Mathematical Sciences, NJ Institute of Technology - University Heights, Newark, NJ 07102, USA.

Received: 11 January 2016 Accepted: 11 January 2016

Published online: 21 January 2016

\section{Reference}

1. Inde ES et al. Safety and efficacy of a $100 \%$ dimethicone pediculocide in school-age children. BMC Pediatrics. 2015;15:70.

\footnotetext{
* Correspondence: eihde@HackensackUMC.org

${ }^{1}$ The Deirdre Imus Environmental Health Center ${ }^{\oplus}$, Hackensack University

Medical Center, 30 Prospect Ave, Hackensack, NJ 07601, USA

Full list of author information is available at the end of the article
}

Submit your next manuscript to BioMed Central and we will help you at every step:

- We accept pre-submission inquiries

- Our selector tool helps you to find the most relevant journal

- We provide round the clock customer support

- Convenient online submission

- Thorough peer review

- Inclusion in PubMed and all major indexing services

- Maximum visibility for your research

Submit your manuscript at

www.biomedcentral.com/submit 


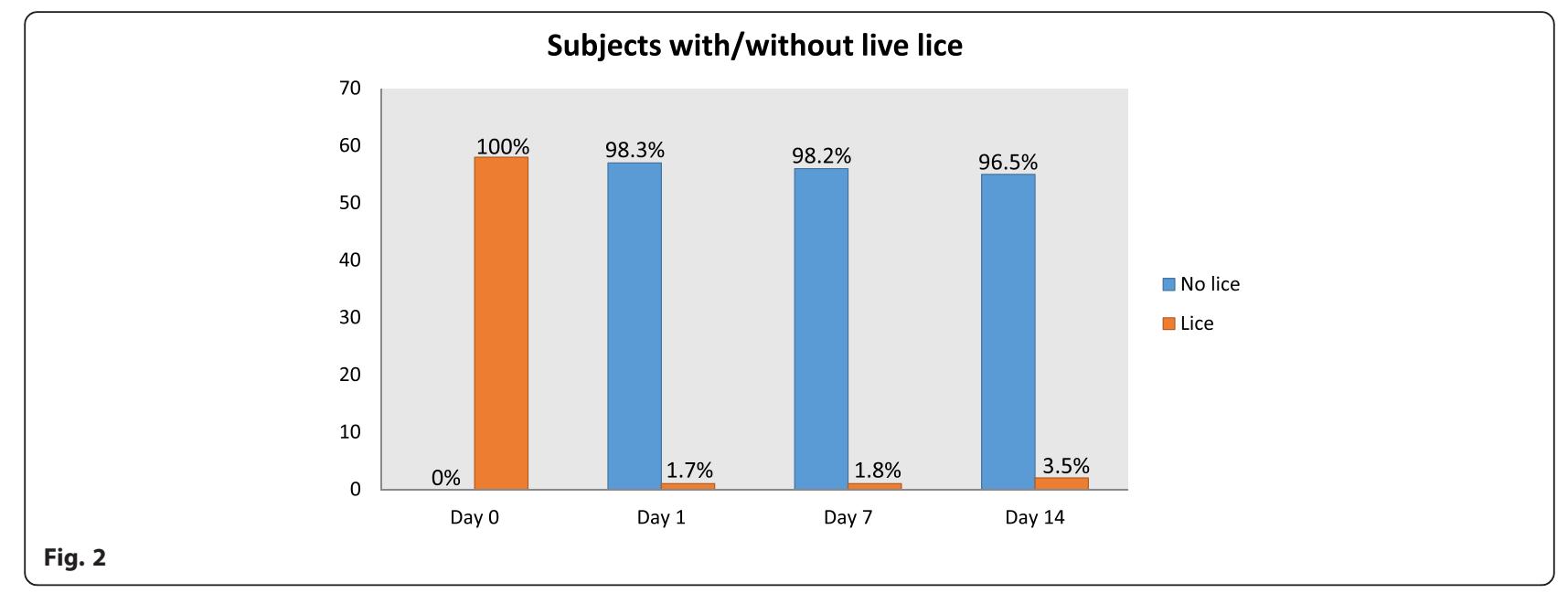

